\title{
REFLEXÕES SOBRE O IMPERATIVO DO GOZO E A MERCADORIZAÇÃO DA CULTURA
}

\section{THOUGHTS ON IMPERATIVE OF ENJOYMENT AND COMMODIFICATION OF CULTURE}

\section{REFLEXIONES SOBRE EL IMPERATIVO DEL GOZO Y LA COMODIFICACION DE LA CULTURA}

\author{
Brunno Fernandes da Silva Gaião \\ Doutor em Administração - Programa de Pós- \\ Graduação em Administração da Universidade \\ Federal de Pernambuco (Propad/UFPE), Recife, \\ Brasil \\ Professor adjunto do Departamento de \\ Administração e Economia (DAEC) - \\ Universidade Estadual da Paraíba (UEPB), \\ Campina Grande, Brasil \\ brunnogaiao@gmail.com \\ André Luiz Maranhão de Souza Leão \\ Doutor pelo Programa de Pós-Graduação em \\ Administração da Universidade Federal de \\ Pernambuco (Propad/UFPE), Recife, Brasil \\ Professor associado do Departamento de Ciências \\ Administrativas da Universidade Federal de \\ Pernambuco (DCA/UFPE) e membro permanente \\ do Programa de Pós-Graduação em \\ Administração da mesma instituição \\ (Propad/UFPE), Recife, Brasil \\ Aleao21@ @otmail.com
}

\author{
Contextus \\ ISSN 1678-2089 \\ ISSNe 2178-9258 \\ Organização: Comitê Científico Interinstitucional \\ Editor Científico: Diego de Queiroz Machado \\ Editor Executivo: Carlos Daniel Andrade \\ Avaliação: double blind review pelo SEER/OJS \\ Recebido em 16/10/2018 \\ Aceito em 16/10/2018 \\ $2^{\mathrm{a}}$ versão aceita em 01/11/2018
}

\section{RESUMO}

Partindo do pensamento žižekiano e tendo em mente o contexto da sociedade pós-industrial contemporânea, este artigo tem por objetivo discutir a relação entre a ideologia do imperativo do gozo vigente e o crescente processo de mercadorização da cultura em nossa época. Abordamos o caso particular do Carnaval do Recife como recurso ilustrativo para conduzir nossa reflexão. A instrumentalização da cultura como recurso a ser aplicado para alcançar o crescimento econômico e sociopolítico estabelece os parâmetros de como as festas populares devem ser realizadas e fruídas. As festas são concebidas, planejadas e preparadas dentro do horizonte da experiência de consumo, podendo ser consideradas objetos de desejo do sujeito-consumidor. A dimensão histórico-cultural é relegada a segundo plano na realização dos eventos. Por meio desta economia libidinal, o capitalismo avança na transformação dos elementos da vida social em mercadorias/objetos de desejo, em prol da manutenção de sua lógica de mercado.

Palavras-chave: imperativo do gozo; ideologia; mercadorização; cultura popular; Carnaval.

\begin{abstract}
Assuming žižekian thinking and having in mind the context of contemporary post-industrial society, this article aims to discuss the relationship between the prevailing ideology of enjoyment and the growing process of commodification of culture in our time. We approach the particular case of Recife's Carnival as an illustrative resource for our reflection. The instrumentalization of culture as a resource to be applied to achieve economic and socio-political growth establishes the parameters of how popular festivals should be held and enjoyed. The parties are conceived, planned, and prepared within the horizon of the consumption experience, and can be considered objects of desire of the subject-consumer. The historical and cultural dimensions are relegated to the background
\end{abstract}


in the realization of events. Through this libidinal economy, capitalism advances in transforming the elements of social life into commodities/objects of desire, supporting the maintenance of its market logic.

Keywords: imperative of enjoyment; ideology; commodification; popular culture; Carnival.

\section{RESUMEN}

Asumiendo el pensamiento žižekiano, este artículo tiene por objetivo discutir la relación entre la ideología del imperativo del goce vigente y el creciente proceso de mercadeo de la cultura en nuestra época. Abordamos el caso particular del Carnaval de Recife como recurso ilustrativo para la conducción de nuestra reflexión. La instrumentalización de la cultura como recurso a ser aplicado para alcanzar el crecimiento económico y sociopolítico establece los parámetros de cómo las fiestas populares deben ser realizadas y disfrutada. Las fiestas son concebidas y planificadas dentro del horizonte de la experiencia de consumo, pudiendo ser consideradas objetos de deseo del sujeto-consumidor. La dimensión histórico-cultural es relegada a segundo plano en la realización de los eventos. Por medio de esta economía libidinal, el capitalismo avanza en la transformación de los elementos de la vida social en mercancías/objetos de deseo, en pro del mantenimiento de su lógica de mercado. Palabras clave: imperativo del gozo; ideología; comodificación; cultura popular; Carnaval.

\section{INTRODUÇÃO}

Vivemos num mundo pós-ideológico? Esta é uma dentre as várias questões presentes na obra do filósofo esloveno Slavoj Žižek. E Žižek nos oferece uma resposta dupla e aparentemente contraditória a esta pergunta: Sim. E não.

Conforme ele argumenta (ŽIŽEK, 1996a), se adotarmos uma concepção “clássica” de ideologia, calcada no pensamento marxiano, podemos afirmar: sim, vivemos num mundo pósideológico. Segundo Karl Marx, agimos de acordo com uma falsa consciência que distorce a realidade social em que estamos inseridos, ignorando as condições efetivas que a produzem. Daí, segundo sentencia Marx, apesar de não termos consciência do que fazemos, fazemos isso. $\mathrm{Na}$ sociedade contemporânea, marcada por uma postura cínica dos indivíduos, não mais acreditamos piamente ou seguimos cegamente "verdades ideológicas". Tais proposições de cunho ideológico são prontamente desacreditadas, ou ao menos identificadas como tal. Eis aqui a razão pela qual Žižek afirma vivermos num mundo pós-ideológico, de acordo com aquilo que poderíamos denominar como concepção “clássica” de ideologia.

Contudo, Žižek (1996a; 2011) nega o entendimento da ideologia como simples e ingênua falsa consciência do indivíduo sobre o mundo, pois para o autor a ideologia, antes de ser uma ilusão sobre a realidade, consiste na própria fantasia que a constitui. Para Žižek, a postura cínica característica de nosso tempo é apenas um álibi que nos permite lavar as mãos enquanto nos mantemos ainda mais embebidos em ideologia. Reformulando a sentença de Marx, Žižek (1996a) afirma que hoje sabemos bem o que estamos fazendo, mas o fazemos. A ideologia não se encontra na dimensão do "saber", na consciência dos indivíduos, mas sim no "fazer", na estrutura inconsciente a reger nossos atos. Ela se encontra tão profundamente 
enraizada em nossas ações que, a despeito do quão consciente estejamos acerca do caráter ideológico de um discurso, isto não nos impede de agirmos em consonância com este discurso. Desta forma, ao nos propormos discutir a atualidade do tema da ideologia, passamos então a trilhar, no rastro de Žižek, o caminho da psicanálise, especificamente aquela de base lacaniana (ŽIŽEK, 2010).

Na perspectiva psicanalítica žižekiana, a fantasia surge como a operação que articula a relação entre o sujeito e o objeto-causa do desejo, inserindo o indivíduo na ordem simbólica, rede do significante por excelência, sua realidade. Logo, nossas fantasias não servem para fugirmos da realidade que nos assola, mas antes são o que estruturam de forma minimamente coerente o nosso mundo, encobrindo a dimensão do Real insondável e insuportável. Esta fantasia, que opera inconscientemente e organiza o funcionamento libidinal do indivíduo, é a ideologia em seu máximo (ŽIŽEK, 1996a; 2010).

Žižek nos oferece uma possibilidade de conciliação entre a crítica à ideologia de origem marxiana, voltada para um nível macro de análise do social, e o olhar psicanalítico da organização libidinal dos sujeitos, voltada para um nível micro de análise. Ao desenvolver sua crítica cultural, resgatando aspectos da crítica da economia política marxiana, Žižek se debruça sobre o funcionamento dos mecanismos ideológicos/libidinais na sociedade contemporânea (ŽIŽEK, 2008a).

Tal sociedade é marcada pela primazia ou pelo imperativo do gozo (ou da jouissance). O que antes era apresentado na forma de proibições a desejos condenáveis, hoje se tornou uma pressão pela satisfação destes desejos, uma imposição do supereu/superego na forma de um dever ético (ŽIŽEK, 2010; ŽIŽEK, 2011). Neste movimento de mudança ideológica, o gozo se torna algo obrigatório; com isso, "nossa política é cada vez mais diretamente a política da jouissance, preocupada com formas de aliciar, ou controlar e regular, a jouissance" (ŽIŽEK, 2008a, p. 408).

O entendimento žižekiano da ubiquidade da ideologia do gozo enquanto constituinte de nossa própria realidade se mostra pertinente num contexto em que presenciamos o crescente processo de mercadorização da cultura (ŽIŽEK, 2011; CANCLINI, 1983; YÚDICE, 2013), especialmente no ocidente. Cada vez mais, a cultura passa a ser regida por uma lógica de mercado, encerrando em si significados específicos. As festas populares, o artesanato, a culinária e tantas outas manifestações culturais são ressignificados pelo mercado e oferecidos como produtos prontos para o consumo (CANCLINI, 1983). 
Nesse sentido, as festas brasileiras são representativas deste fenômeno, sendo o carnaval possivelmente seu caso mais emblemático. Ao longo dos últimos séculos, o carnaval brasileiro, que pode ser considerada a festa popular mais próxima da nossa identidade cultural (DAMATTA, 1997), passou por inúmeras transformações, sob a influência de forças diversas - religiosas, políticas, econômicas, sociais. As contingências históricas e econômicas moldaram pouco a pouco as versões brasileiras da celebração de Momo, num processo de constante reinvenção e renovação da festa, que tem como principais expoentes nacionais os estados do Rio de Janeiro, da Bahia e de Pernambuco. (MUNIZ, 2006). A festa carnavalesca, juntamente com tantos outros festejos, compõe agora um circuito de eventos-espetáculo cosmopolitas, planejados com vistas para o forte apelo mercadológico das atividades neles desenvolvidas, voltados para a prestação de serviços de diversão. Tais eventos se localizam no fluxo das redes midiáticas, nas quais símbolos são insumos e mercadorias a um só tempo, estando amalgamadas produção e expressão cultural (FARIAS, 2008). Percebemos então um movimento de mercadorização desta festa específica, manifestação que aponta para um processo mais abrangente que alcança a cultura popular como um todo, como indicado por autores como Canclini (1983) e Yúdice (2013).

Partindo da teoria žižekiana e tendo em mente o contexto da sociedade pós-industrial contemporânea, este ensaio tem por objetivo discutir a relação existente entre a ideologia vigente do imperativo do gozo e o crescente processo de mercadorização da cultura em nossa época. Assim, buscamos refletir sobre as consequências deste processo para a sociedade. Para tanto recorreremos ao caso particular do Carnaval, especialmente a festa da cidade do Recife, como recurso ilustrativo que nos auxilie a conduzir a reflexão. Assim, a seguir apresentaremos uma breve reconstituição histórica da trajetória da festa de carnaval e, num segundo momento, discutiremos as bases teóricas do pensamento žižekiano e qual sua possível contribuição para a análise da realidade da mercadorização da cultura na contemporaneidade.

\section{O CARNAVAL E SUAS ORIGENS}

O carnaval é tido por alguns como a mais antiga manifestação das festas populares, estabelecido no senso comum como o período de diversão e folia que precede a quaresma e destacando-se por conservar ainda hoje práticas históricas. Em suas origens, temos a festa carnavalesca associada ao culto à fertilidade da natureza como uma constante em diferentes culturas antigas. Egípcios, gregos e romanos celebravam o carnaval com danças, brincadeiras 
e festejos em homenagem a diferentes divindades (ARAÚJO, 2000; CARNEIRO, 2006). Em todas estas civilizações, a ruptura com a rotina cotidiana, a entrega aos prazeres e os exageros se faziam presentes na celebração, caracterizando um "tempo extraordinário" (SEBE, 1986; ARAÚJO, 2000). Assim, apesar da sua evidente ligação com o cristianismo, o carnaval não foi criado pela Igreja Católica. Na verdade, no período da Idade Média, o que houve foi uma incorporação das práticas ritualísticas da festa popular pelas tradições cristãs.

O carnaval contemporâneo apresenta diferentes variações da festa de carnaval ao redor do mundo, modificadas de acordo com suas particularidades locais. Em comum entre as variações da festa está o senso de inversão de valores e oposição à vida cotidiana (BATISTA; ÁVILA, 2006). Ao tratarmos da história do carnaval no Brasil, o primeiro ponto a ser destacado é a diversidade de influências na configuração da festa. Além do entrudo português, difundido amplamente no séc. XVII (SEBE, 1986; GERMANO, 1999; ARAÚJO, 2000; BATISTA; ÁVILA, 2006; NOGUEIRA, 2008; DELGADO, 2012; ARANTES, 2013; JAGUARIBE, 2013), a influência africana e indígena também se fez presente na constituição da festa brasileira (SEBE, 1986). Hoje, as cidades do Rio de Janeiro, Salvador, Recife e Olinda se destacam como os principais polos da festa no país (ARAÚJO, 2000).

No que diz respeito especificamente ao carnaval de Recife, a origem da festa remonta ao final do século XVII, quando carregadores de açúcar e outras mercadorias se reuniam para celebrar a Festa de Reis. Hoje, na cidade do Recife, o carnaval promovido pela gestão pública é predominantemente gratuito e ocorre nas ruas (ARAÚJO, 2000). A partir de 2001, o evento sofreu uma modificação no modelo. A prefeitura lançou o Carnaval Multicultural do Recife, valorizando a diversidade cultural e adotando os conceitos de multiculturalismo e descentralização. A festa passou a envolver a instalação de "polos de animação" espalhados por toda a cidade, oferecendo uma maior diversidade de atrações (GAIÃO; LEÃO; MELLO, 2014; PREFEITURA DO RECIFE, 2015; VIDAL; ANDRADE, 2009). Com as mudanças de gestão, nos últimos anos a prefeitura deixou de lado o termo "multicultural", contudo preservou o modelo consolidado ao longo da última década.

\subsection{Olhares sobre o Carnaval}

Ao longo dos séculos, a festa de carnaval foi abordada sob diferentes perspectivas. Para Bakhtin (BAKHTIN, 1987), a cultura popular na Idade Média e Renascimento era a cultura 
cômica, com expressão máxima no carnaval (SOIHET, 1998), não se restringindo apenas aos períodos pré-definidos para os festejos, mas permeando o cotidiano da vida do povo. O riso carnavalesco seria o alicerce da cultura popular da época, e a carnavalização da vida representaria o mecanismo de oposição à cultura oficial que privilegiava o Estado e a Igreja (BAKHTIN, 1987; DELGADO, 2012). A cultura cômica popular, tendo como expoente máximo o carnaval, funcionaria como um mecanismo de resistência do povo, oferecendo a possibilidade de transgredir a estrutura rígida da cultura oficial, satirizando-a e permitindo à população viver uma espécie de mundo paralelo, livre das opressões. Assim, Bakhtin enxerga o carnaval como "rito de inversão" que subverte as regras sociais (SCRIBNER, 1978; RISÉRIO, 1995). Tal inversão representaria uma ideia de plenitude social, na qual a igualdade entre os indivíduos superaria as hierarquias existentes (LAMPOGLIA; MIOTELLO; ROMÃO, 2011).

O constrangimento da vida oficial, vinculada diretamente ao Estado e à Igreja, seria suspenso em favor da libertação proporcionada pelo riso subversivo presente na cultura popular (BAKHTIN, 1987). A degradação presente no realismo grotesco da cultura medieval é elemento central do riso carnavalesco (CARLSON, 1990). O carnaval seria a realização plena das qualidades humanas, livres das amarras sociais e desigualdades. A vida oficial, uma "não vida”, cederia espaço à espontaneidade irrefreável da natureza humana (LEOPOLDI, 2010). O carnaval é a expressão máxima da possibilidade de superação das limitações sociais, o espaço supremo de revolução e subversão dos constrangimentos sofridos pelo povo (BAKHTIN, 1987). Contudo, cabe questionarmos se esta possibilidade de liberdade não seria ela mesma limitada e regulada, funcionando como válvula de escape catártica para as pressões do controle do Estado e da Igreja sobre o povo.

Voltando-nos para o contexto do festejo carnavalesco no Brasil, DaMatta (1997) o entende como catarse coletiva, na qual o povo tem a oportunidade de inverter as regras e costumes da sociedade por um breve período. O carnaval permitiria a possibilidade de denunciar o poder dominante por meio da liberdade criativa e de expressão (JAGUARIBE, 2013). Segundo Delgado (2012, p. 9), para “DaMatta (1990), o carnaval contém uma essência igualitária, onde as relações de espontaneidade e afetividade vividas em 'casa' extrapolam para a 'rua', o espaço da rua se transforma temporariamente no espaço de casa". Neste ponto, a análise de DaMatta se aproxima da visão de Bakhtin acerca dos festejos carnavalescos (RISÉRIO, 1995; DELGADO, 2012) ao tratar o fenômeno como um espaço para inverter a cultura oficial e as estruturas de relações cotidianas. 
Em relação a esta questão, Maria Isaura Pereira de Queiroz (1992) é contundente, negando a visão de DaMatta do carnaval como período de exceção. Para a autora, o carnaval é permeado por distinções de classe, com espaços e papéis específicos para os indivíduos. A inversão se limitaria aos sentimentos e expectativas dos foliões, nunca alcançando o nível da estrutura social (PERNY; MELLO, 2013). A festa não inverteria desigualdades, apenas demostraria o desejo latente de que estas desigualdades fossem de alguma forma superadas (RISÉRIO, 1995).

\section{CULTURA POPULAR E A MERCADORIZAÇÃO DA CULTURA}

Hoje, de acordo com Hiram Araújo (2000), a festa carnavalesca pode ser entendida como um reflexo das mudanças da própria sociedade, cada vez mais lúdica e fragmentada. Dionísio (representante do prazer e da festa) parece sobrepor-se a Apolo (a racionalidade e a ordem) num processo de carnavalização do cotidiano. Para Araújo, o carnaval se perpetua como celebração cristã, adaptação de rituais pagãos. Contudo, não podemos ignorar a mercadorização da festa. Apesar de sua dimensão popular, o carnaval tornou-se um evento midiático idealizado pelas elites urbanas, devendo "converter-se num belo espetáculo, produzido pelas camadas ricas e letradas, para ser contemplado e aplaudido por todos" (ARAÚJO, 1997, p. 204).

O carnaval deixa de ser simples manifestação cultural popular e se torna produto cultural a ser explorado economicamente dentro de um sistema de mercado capitalista. Podemos assumir que este movimento representa a "transição do carnaval enquanto expressão cultural e espaço de enfrentamentos para o carnaval-produto ou o carnaval-indústria, deslegitimando-o enquanto experiência cultural em si” (VISCARDI; SOTTANI; SILVA, 2013, p. 16). O carnaval, transformado em produto cultural, é um fenômeno ainda mais complexo do que antes, reflexo das mudanças decorrentes do estabelecimento de uma cultura de consumo (FARIAS, 2003).

O carnaval é mais uma manifestação da apropriação da cultura popular pela lógica de mercado, processo cada vez mais comum nas últimas décadas (CANCLINI, 1983). Festas populares, artesanato, culinária e tantas outas manifestações culturais são ressignificadas pelo mercado e oferecidas como alternativas de produtos para o consumo. Para Canclini (1983), as festas populares não devem ser enxergadas como momentos de exceção. Ao contrário, encontramos na festa uma "ocasião na qual a sociedade penetra no mais profundo de si mesma, 
naquilo que habitualmente lhe escapa" (CANCLINI, 1983, p. 54). A festa concede forma e ordem para manifestar pulsões reprimidas pelo cotidiano da vida social. Práticas sociais são estruturadas para dar vazão a esta energia. Contudo, tais práticas apresentam continuidade com a existência cotidiana, de modo que "as diferenças sociais e econômicas nela se repetem" (CANCLINI, 1983, p. 55), perpetuando contradições presentes na sociedade.

Neste processo de apropriação da cultura popular pelo capital, o sentido material e o cultural se afastam um do outro em favor de uma organização capitalista e uma lógica de mercado crescente. As manifestações culturais populares tornam-se mercadorias a serem desenvolvidas de acordo com os diferentes interesses econômicos, não mais simplesmente como expressão material e simbólica de uma cultura (CANCLINI, 1983).

Na contemporaneidade, a cultura é tratada como uma cultura de globalização acelerada, instrumentalizada como recurso a ser aplicado para alcançar crescimento econômico e melhoria sociopolítica, naquilo que pode ser denominado "capitalismo cultural". Tantas diferentes dimensões da cultura popular quantas forem passíveis de serem assimiladas pela lógica de mercado "são mobilizadas como recursos para o turismo e para a promoção das indústrias que exploram o patrimônio cultural" (YÚDICE, 2013, p. 17). Somente segmentos da cultura com potencial para gerar retorno econômico e social recebem investimentos, em detrimento de manifestações culturais menos atrativas para esta lógica do capital (YÚDICE, 2013).

Assim, estabelece-se uma economia política específica: a economia cultural, mola propulsora do desenvolvimento social e do crescimento econômico, que transforma a cultura na própria lógica do capitalismo atual. Utiliza-se a cultura para fins de desenvolvimento urbano, assim como se exploram manifestações culturais locais para o turismo, localidades históricas tornam-se parques temáticos, e propriedades intelectuais são tratadas como bens culturais a fim de promover o fluxo e acúmulo de capital. Diante do imbricamento mútuo da cultura e da economia, até mesmo as manifestações de resistência e tentativas de emancipação parecem ser assimiladas pelo sistema a que se opõem. Com a culturalização da economia, as inovações nos campos da tecnologia e da comunicação, juntamente com a exploração crescente e pujante do trabalho cultural e intelectual, dão origem a uma nova divisão de trabalho (YÚDICE, 2013).

O carnaval, dentre tantas outras manifestações, transforma-se em mais uma mercadoria comercializada por agentes diversos, tais como o Estado, empresários, mídia, artistas, comerciantes etc. (CARNEIRO, 2006). O interesse econômico nas festas se torna cada vez maior, e a cultura popular passa a ser pensada em escala global, tendo em vista atender os 
interesses do mercado (TRIGUEIRO, 2005). Como consequência, constrói-se uma relação de conveniência entre a globalização e a cultura, na qual processos simbólicos são propagados globalmente de maneira a propiciar o desenvolvimento econômico esperado e a adequação política de forma crescente (YÚDICE, 2013). Desta forma, as festas populares passam a ser gradualmente transformadas em eventos-espetáculos cuidadosamente planejados, produzidos e oferecidos para consumo à população, fontes de experiências extraordinárias a serem buscadas em série pelos indivíduos enquanto consumidores, numa espécie de coleção de troféus experienciais de gozo conquistados (KRIER; SWART, 2016). Este processo de mercadorização resulta no enquadramento dos espetáculos em parâmetros de padronização e universalização das experiências a serem fruídas pelos indivíduos (YOLAL, 2016).

Percebemos a mudança da análise em relação às festas populares entre Bakhtin, de um lado, e Canclini e Yúdice, do outro. Enquanto a cultura popular na Idade Média era permeada pelo riso carnavalesco que subverte a cultura oficial e oferece a possibilidade de uma "outra vida" à população, a cultura popular atual é pautada pelo capital e pela lógica de mercado, moldada e limitada em suas práticas. Partindo deste contraponto, diante da realidade de mercadorização da cultura, adotaremos uma postura crítica, pós-marxista. Assim, a partir da próxima sessão, apresentaremos o pensamento do filósofo Slavoj Žižek, demonstrando como este pode ser aplicado para analisar o fenômeno no contexto da sociedade de consumo contemporânea.

\section{SLAVOJ ŽIŽEK E A CRÍTICA PSICANALÍTICA DA IDEOLOGIA}

Em sua obra, o filósofo e psicanalista Slavoj Žižek analisa a cultura e a política contemporâneas buscando desenvolver uma nova possibilidade estudar a ideologia (MYERS, 2003; ŽIŽEK, 2008a). As principais bases do autor são a filosofia hegeliana, a economia política marxiana e a psicanálise lacaniana.

No que compete à Hegel, Žižek afirma que a dialética hegeliana é uma ferramenta para explicar a ideologia, ferramenta esta que não produz um consenso, mas sim uma contradição. A tensão dialética entre tese e antítese é a condição interna de cada identidade e a instância em que se estabelece a verdade. Quanto a Marx, Žižek adota a crítica marxiana como motivação de seu pensamento, perspectiva que orienta sua abordagem do tema da ideologia. Por fim, Žižek recorre a Lacan enquanto meio para analisar o processo de constituição do sujeito e sua maneira 
de ser dentro da sociedade (MYERS, 2003).

Assim, pode-se definir como objetivo de Žižek resgatar e repensar o materialismo dialético por meio de Lacan e Hegel, utilizando-o como opção mais adequada para tratar da diferença e da contingência e contribuir para a crítica à ideologia (ŽIŽEK, 2008a). A seguir, apresentaremos brevemente aspectos relacionados à base psicanalítica da teoria žižekiana e como ele a emprega para conceber sua crítica à ideologia contemporânea.

\subsection{A base psicanalítica zižekiana}

Utilizando bases da linguística saussuriana e da antropologia estrutural de Lévi-Strauss, Lacan propõe um novo olhar sobre a psicanálise ao estabelecer que o inconsciente é estruturado como linguagem (FINK, 1998; SARUP, 1993). Segundo ele, não há separação entre o self e a sociedade. O ser humano é socializado ao apropriar-se da linguagem, e é esta que o constitui enquanto sujeito, não havendo sujeito fora da linguagem (SARUP, 1993). Nascemos num mundo de discurso e disto não podemos fugir. Na verdade, estamos inseridos na cadeia do significante, na ordem simbólica da linguagem, antes mesmo de nascermos, e continuaremos presos a ela até mesmo despois de morrermos (FRANÇOIA, 2007; FINK, 1998). Uma vez que a linguagem é limitada, faltam-nos palavras para nomear por completo o mundo ao nosso redor. Ela nos permite apenas aproximações daquilo que representamos. Não podemos dizer tudo, surgindo deste fato a falta estrutural que nos constitui e remete ao mal-estar apontado por Freud. Sendo assim, "o homem é incompleto porque fala" (TEIXEIRA; COUTO, 2010, p. 584).

Diante desta condição de ser imerso na linguagem, Lacan desenvolve três conceitos novos para a psicanálise. Juntos, compõem a tríade das ordens do funcionamento mental que dão forma à nossa realidade: o Imaginário, o Simbólico e o Real (ŽIŽEK, 2010).

O Imaginário consiste no processo por meio do qual o ego é concebido, como tentativa de conciliar a diferença entre si mesmo e a imagem de integridade com a qual o indivíduo se identifica, ou seja, a distinção entre si e a imagem de si. Lacan se refere a este nível como a primeira articulação do Eu, naquilo que ele chama de Estágio do Espelho (LACAN, 1996). Neste estágio, ainda nos primeiros meses de vida, a criança se reconhece em seu reflexo no espelho e passa a se perceber como um indivíduo (SARUP, 1993; MYERS, 2003).

O Simbólico, por sua vez, consiste na realidade significada, espaço no qual tomamos nosso lugar e nos deparamos com o "Grande Outro", sujeito simbólico da alteridade (MYERS, 
2003). É o espaço simbólico da linguagem, do qual não há volta e que nos impõe as regras do jogo. Recorrendo à linguística, podemos identificar dois níveis na Ordem Simbólica: a estrutura formal "vazia" - dimensão do significante - e os elementos que preenchem os lugares vazios, dimensão do significado (ŽIŽEK, 2008a).

O nosso pensamento ocorre sempre dentro da Ordem Simbólica. Logo, enquanto pensarmos, a linguagem será indispensável. É neste sentido que Lacan afirma: "a letra mata”. A linguagem surge e sobrepõe-se ao que havia antes dela, ao Real (FINK, 1998). Completando a tríade, este Real consiste no espaço além da significação da Ordem Simbólica, que escapa à linguagem e, portanto, não pode ser conhecido (ŽIŽEK, 2010; MYERS, 2003). Podemos imaginar o Real como uma superfície plena, sem falhas ou emendas, tudo o que existe. A linguagem simboliza este Real, repartindo-o, classificando-o dentro de estruturas, eliminandoo. Em seu lugar, surge a malha da realidade, produto da Ordem Simbólica, do reino da linguagem. Assim, a existência de algo em uma dada realidade passa pela linguagem.

Segundo Fink (1998, p. 44), podemos compreender o Real simplesmente como "aquilo que ainda não foi simbolizado, resta ser simbolizado ou até resiste à simbolização”. Contudo, Žižek vai além e afirma que o Real lacaniano não se sustenta enquanto positividade, mas apenas enquanto a lacuna presente na multiplicidade de pontos de vista a seu respeito. O Real paralático žižekiano vai além da noção padrão lacaniana de Real como dimensão estável, independente dos diferentes universos simbólicos possíveis. O Real paralático é a virtualidade constituída retroativamente exatamente pela miríade de formações simbólicas, explicando a própria multiplicidade de realidades (ŽIŽEK, 2008a).

Ao resistir ao processo de simbolização, o Real se manifesta como objeto $a$, o resto que sobra do processo de simbolização, seu resíduo. Ele oferece ao sujeito a ilusão da possibilidade de completude, gerando o que Lacan chama de fantasia do sujeito: a relação fantasmática que se estabelece entre o sujeito e o objeto $a$. O prazer construído pelo sujeito em sua fantasia de finalmente reencontrar o objeto $a$ e ver-se enquanto um sujeito completo é denominado por Lacan de jouissance ou gozo (FINK, 1998). O objeto $a$ é uma entidade sem substância, "que não é nada senão a inscrição do próprio objeto no campo dos objetos, sob a aparência de um borrão que só ganha forma quando parte desse campo é anamorficamente distorcida pelo desejo do sujeito" (ŽIŽEK, 2010, p. 87). Cabe aqui ressaltar a diferença entre o objeto de desejo e o objeto $a$, ou objeto causa do desejo: enquanto o primeiro é o mero objeto desejado pelo sujeito, o segundo é o traço que desperta o desejo propriamente dito no sujeito, aquilo que faz de um objeto qualquer algo digno de desejo (ŽIŽEK, 2010). 
O sujeito surge apenas a partir do objeto $a$, algum resto ou excesso que resiste à subjetivação. A barra sobre o $\mathrm{S}$ do sujeito (\$) na teoria lacaniana remete ao fato de que não há significante capaz de representar adequadamente este sujeito, apenas o objeto é capaz de preencher de forma fantasmática o vazio de subjetividade de \$ e produzir um semblante de sujeito (ŽIŽEK, 2000). Assim, o sujeito não existe enquanto substância. Como o sujeito estabelece o objeto de seu desejo através da sua relação com a ordem simbólica, o indivíduo se constitui enquanto sujeito desejante na relação que estabelece com o vazio da ordem simbólica, relação esta mediada pela fantasia (ŽIŽEK, 2008a).

É a partir da discrepância ente Real e Simbólico que pode emergir o sujeito. Caso houvesse uma correspondência perfeita e inequívoca entre Real e Simbólico, não haveria espaço para a subjetividade. É no espaço desta discrepância que surgem as cadeias de significantes especificas que nos subjetivam. Assim, o sujeito é constituído, na verdade, pela negatividade, pelo vazio que representa devido à não correspondência entre Real e Simbólico (MYERS, 2003). O sujeito lacaniano se afasta do entendimento do sujeito consciente, cartesiano, dado que este último se encontra no nível do self, e Lacan considera não haver "self verdadeiro", mas apenas uma construção mental fruto da fase do espelho. O sujeito lacaniano é o sujeito do inconsciente, um furo na estrutura discursiva da Ordem Simbólica, um sujeito como falta a ser, representado como sujeito barrado, “\$” (FINK, 1998).

O sujeito não existe enquanto substância, mas constitui-se na relação paralática que estabelece com o Outro, numa lógica dialética de relação sujeito-objeto. O sujeito é o reflexo do objeto: aquilo que o objeto, ou o Outro, assujeita (ŽIŽEK, 2008a; 2010). O sujeito advém da sujeição do indivíduo pela linguagem, originando uma possibilidade de ser. O sujeito passa a ocupar um lugar determinado dentro da Ordem Simbólica, contudo um lugar vazio.

\subsection{Ideologia e imperativo do gozo}

Partindo dos conceitos abordados acima, Žižek trabalha a ideologia como sendo não apenas a falsa consciência ou representação ilusória da realidade. A ideologia se reduz à própria realidade, cuja existência implica não conhecimento da parte de seus participantes. Ideológico não é a falsa consciência do ser social, mas sim o próprio ser social enquanto suportado por esta falsa consciência (ŽIŽEK, 2008b). A ideologia, em vez de uma ilusão para fugirmos da realidade, revela-se como fantasia que serve para nos ajudar a suportar a própria realidade: a 
função da ideologia consiste em oferecer a realidade social que nos permite escapar de elementos traumáticos do Real. Fora da "falsa consciência" marxista, a ideologia surge como ilusão socialmente necessária, perspectiva pautada no entendimento da psicanálise acerca do fetichismo, que leva o sujeito a agir como se não soubesse o que está fazendo, enquanto consome imagens ilusórias (ŽIŽEK, 2008b).

$\mathrm{Na}$ contemporaneidade já temos consciência da distorção existente em nosso entendimento da realidade, contudo adotamos uma postura cínica na qual, mesmo sabendo da existência da ideologia, continuamos agindo de acordo com ela. Entretanto, acreditar, longe de ser puramente um estado mental, materializa-se em nossas atividades sociais efetivas. Logo, a mistificação da ideologia não está localizada na dimensão do "saber", mas sim naquela do "fazer", no nível das nossas práticas cotidianas (ŽIŽEK, 2008b). Daí a afirmação de nos encontrarmos em uma época supostamente pós-ideológica, sustentada exatamente pelo fato de a ideologia não funcionar mais numa lógica sintomal, com a construção ideológica comprometida pela irrupção de sintomas que rasgariam sua superfície simbólica, mas sim numa lógica fetichista, segundo a qual o próprio sintoma é, enquanto exceção perturbadora, incorporado e aceito como a forma de lidar com a inconsistência do edifício ideológico (ŽIŽEK, 2011).

Este entendimento da ideologia a partir de uma concepção psicanalítica também passa pela contribuição teórica de Louis Althusser. A teoria da ideologia de Althusser é precisa ao reconhecer a lacuna entre os níveis da experiência ideológica individual (o processo de interpelação) e o aparato material que a sustenta (os aparelhos ideológicos). A ideologia opera no espaço das regulações não faladas, implícitas, com as quais o sujeito tem uma relação não reflexiva. É o ar que nos rodeia e que respiramos espontaneamente em nossas interações diárias, em ações que aceitamos por julgarmos naturais (ŽIŽEK, 2014). Conforme defende Althusser, ser materialista significa para o marxismo tradicional conceber a ideologia como alicerçada em um processo material extraideológico de (re) produção social. Contudo, perde-se de vista aqui a existência material da ideologia em si nos Aparelhos Ideológicos de Estado (ALTHUSSER, 1996) como definidos por Althusser por meio das práticas e rituais institucionalizados (ŽIŽEK, 2014). Žižek, em contrapartida, vai além da proposição althusseriana, relembrando Lacan ao indicar uma materialidade específica das ideias, imanente à Ordem Simbólica. Esta máquina sem significado preciso equivale ao que Lacan chamou de Grande Outro, que opera além de quaisquer materializações concretas em práticas ou rituais institucionalizados (ŽIŽEK, 2014).

Ainda em relação a Althusser, Žižek destaca como outra limitação de sua teoria da 
ideologia sua incapacidade de perceber a complexidade do processo de interpelação. Althusser não percebe que, antes do reconhecimento ideológico, há um breve momento de interpelação sem identificação. Logo, o indivíduo constitui-se como "sempre-já" sujeito. Há um sujeito que precede o processo de subjetivação em si, de identificação simbólica. Este "sempre-já" sujeito é o sujeito barrado (\$) da teoria lacaniana, o sujeito do vazio (ŽIŽEK, 2014).

Sob a ótica de Žižek, a ideologia permeia toda a sociedade, pautando nossas concepções e conduzindo-nos a reproduzir e fortalecer conceitos já estabelecidos na realidade social em que estamos imersos. Assim, o sujeito surge como mera manifestação simbólica da ordem vigente, por ele mesmo reproduzida (LUSTOSA; PIRES, 2012). Neste ponto, cumpre ressaltar a existência do espectro da ideologia: a falha dela em acomodar todos os aspectos do Real dentro da realidade (Ordem Simbólica), acabando por revelar, em relação a esta, o caráter de construção ideológica (ŽIŽEK, 1996b).

A ideologia seria, então, o modo como se constrói a ficção da autoidentidade por meio da estrutura da linguagem e, de modo mais abrangente, pela ordem simbólica - qualquer sistema de comunicação, como a linguagem, o discurso, o sistema de troca monetária. Assim, a ideologia não consiste em uma ilusão para fugirmos da realidade. Pautados pela ideologia, elaboramos as nossas fantasias como mecanismos de construção/suporte da própria realidade, o que nos permite escapar de elementos traumáticos do Real. Tais fantasias são construídas em torno do vazio da ordem simbólica, sendo exatamente a partir deste vazio que estabelecemos o (s) objeto (s) do nosso desejo: a fantasia, de forma inconsciente, nos ensina o que e como desejar. A frustração proveniente da incapacidade de realizar nosso desejo - visto nosso desejo ser construído em torno do vazio estrutural da ordem simbólica - dá origem ao gozo, à pulsão que nos anima dentro da dimensão simbólica (ŽIŽEK, 1996a; 2008a; 2008b).

As ideologias dominantes da atualidade apresentam em comum a primazia pelo gozo. Surge então uma imposição do imperativo do gozo. O que antes se apresentava na forma de proibições a desejos condenáveis tornou-se hoje uma pressão para satisfazer tais desejos. Neste movimento de mudança ideológica, o gozo se tornou algo obrigatório (ŽIŽEK, 2008a). Este imperativo inverte o imperativo ético kantiano "Você pode, porque deve", transformando-o na injunção superegoica "Você deve, porque pode!". O superego atua pressionando o sujeito ao gozo incessante e, paradoxalmente, impossível. O sujeito é convocado a um dever, interpelado eticamente a gozar (ŽIŽEK, 2000).

Uma vez que, na sociedade contemporânea, transferimos as relações entre pessoas para 
as relações entre coisas (mercadorias), "a cultura de consumo encontra seu perfeito complemento num superego dedicado ao gozo" (KUL-WANT; PIERO, 2012, p. 107). Nosso desejo não gira mais em torno do proibido e inatingível ao gozo, sempre ausente, mas constituise em função dos objetos de desejo sempre presentes, que dão origem a um círculo vicioso de gozo insaciável (KUL-WANT; PIERO, 2012).

Nesta lógica perversa do capitalismo, a mercadoria é, enquanto particularidade concreta, tida como desnecessária. São as imagens fantasmáticas que passam a ser compreendidas como fonte de desejo e valor (FONTENELLE, 2005). Visto o ato de consumo destruir o objeto representante da fonte de gozo, o consumidor carece de substituí-lo. Assim, o sublime objeto de desejo, fonte de gozo, transfere-se e materializa-se em objetos particulares concretos, portadores efêmeros da função de satisfazer o consumidor (RAMOS, 2007). É a partir desta lógica de necessidade de constante substituição de bens que o sistema capitalista se perpetua num ciclo constante de obsolescência acelerada das mercadorias, ou objetos de desejo (ŽIŽEK, 2000).

Este imperativo do gozo se torna a lei (RAMOS, 2007) e conduz o indivíduo a um sentimento de infelicidade. Temos que consumir, comprar, comer, transar... Aproveitar a vida a cada instante. No entanto, não é o gozo o que alcançamos, mas uma ideia simulada de gozo (KUL-WANT; PIERO, 2012; CEDERSTRÖM; SPICER, 2015). O indivíduo, no papel de consumidor, encontra-se em meio ao dilema de, por um lado, satisfazer a pulsão de gozo ditada pelo Outro (ordem simbólica coletiva) da ideologia de consumo e, por outro lado, perceber-se insatisfeito a todo instante com as respostas que o sistema the oferece para atender a seus desejos (RAMOS, 2007). Tal impossibilidade de atender plenamente ao mandado superegoico do gozo gera um sentimento de culpa constante (CEDERSTRÖM; SPICER, 2015).

O método ideológico por excelência reduz-se a naturalizar e universalizar afirmações e crenças, daí a meta da crítica à ideologia dever ser denunciar essa falsa universalidade/naturalidade. Existem duas formas de realizar a crítica à ideologia: a) a forma discursiva, que revela a ideologia como um conjunto de significantes dispersos totalizados em torno de pontos nodais - o que remete à Teoria do Discurso de Laclau e Mouffe (1985); e b) a voltada a extrair o núcleo do gozo, articulando a forma em que a ideologia implica, manipula e produz um gozo pré-ideológico, estruturado na fantasia (ŽIŽEK, 1996a). É através deste segundo caminho que Žižek argumenta ser possível desvelar os mecanismos atuantes no nível ideológico na sociedade contemporânea. Tal abordagem da crítica à ideologia parte da premissa da psicanálise lacaniana de toda ordem social ser marcada por um excesso libidinal a 
impulsionar as ações dos indivíduos de forma inconsciente e inexorável: a jouissance ou gozo. Žižek investiga, então, a formação das ideologias num contexto de mudanças deste excesso libidinal, bem como da economia política do capitalismo tardio (FELDNER; VIGHI, 2009).

\section{IMPERATIVO DO GOZO E MERCADORIZAÇÃO DA CULTURA}

Apesar da contestação pertinente do uso do termo "pós-moderno" para designar uma nova ideologia emergente, a proposição de Lyotard estabeleceu um novo significante-mestre que descrevia um momento de mudança sócio-histórica. No nível do consumo, um dos principais fatores deste momento pós-68 foi o fortalecimento do "capitalismo cultural” (ŽIŽEK, 2011), marcado tanto pela mercadorização da cultura quanto pela culturalização da economia de mercado. A cultura é cada vez menos uma dimensão específica e isolada do mercado, mas sim seu componente central. Este movimento, conforme defende Žižek, é evidente especialmente na cena artística, contudo acreditamos que esta realidade pode ser extrapolada para as demais esferas do mercado, produzindo um aparato econômico-cultural em que este curto-circuito entre cultura e mercado exige a constante necessidade de gerar produtos que choquem e "revolucionem" a cada instante, com vistas a reproduzir-se (ŽIŽEK, 2000).

O consumo passa a orientar-se por três dimensões que se mostram correlatas com a tríade lacaniana do Real-Simbólico-Imaginário, na qual o último nível se sobrepõe cada vez mais sobre os outros: não mais compramos pela utilidade direta - chamada por Marx de valor de uso (Real) - nem pelo símbolo de status, como na tese do consumo conspícuo de Veblen (Simbólico), mas sim pela experiência prazerosa e significativa (Imaginário) que o consumo pode nos oferecer (ŽIŽEK, 2011). É difundida na sociedade contemporânea a ideia de que o consumo deve sustentar "a qualidade da vida, seu tempo deveria ser um 'tempo de qualidade' - não tempo de alienação, de imitação de modelos impostos pela sociedade [...], mas tempo de realização autêntica de meu verdadeiro Eu, do jogo sensual da experiência” (ŽIŽEK, 2011, p. 53), entretanto não é esta realidade pura e simples a que encontramos cotidianamente.

$\mathrm{Na}$ atual sociedade permissiva que encaramos, organizada sob a égide do gozo numa ideologia do supereu hedonista, vemos articulados aqui diferentes discursos, num cenário em que a autoridade é exercida pelo saber sem rosto de um conhecimento impessoal e inquestionável em prol de uma lógica capitalista. Nesse mesmo cenário, concede-se ao sujeito histericizado a angustiante liberdade de escolha entre infinitas opções de mercadorias, objetos 
$a$ por excelência, materializações da promessa de completude que nos seduz e nos move rumo a um gozo sempre parcial (ŽIŽEK, 2011). O gozo é assim alçado à posição de fator econômico central (MADRA; OZSELÇUK, 2010) na medida em que constitui uma configuração social pautada em uma economia do gozo (BECKER, 2010). Esta economia libidinal passa a objeto central de reflexão voltada para entender a dinâmica social, econômica e política que se estabelece na sociedade contemporânea. Compreender o gozo como fator econômico permite compreender a configuração do tecido social que esta posta (SAFATLE, 2008).

Neste cenário, consolida-se a Lei do supereu, a Lei do gozo obsceno. Antes tínhamos a Lei pública patriarcal como ideal do eu, no nível da ordem simbólica que regula e orienta o espaço social, e a Lei do supereu como seu suporte obsceno que permitia a transgressão da Lei simbólica como uma forma específica de gozo, fonte última da unidade de uma comunidade. Hoje, em contrapartida, temos uma lei pública igualitária que, ao ser transgredida, dá lugar a uma lei superegoica autoritária, e esta não cessa de determinar nossas atitudes e demandar o gozo (ŽIŽEK, 2006; SAFATLE, 2008). Neste sentido, Vladimir Safatle (2004, p. 15) alerta para este caráter: "quando o gozo se transforma em Lei, o direito ao gozo aparece como um imperativo ainda mais difícil de suportar. Lacan nos lembrou deste ponto ao afirmar que o verdadeiro imperativo do supereu na contemporaneidade é: 'Goza!', ou seja, o gozo transformado em uma obrigação".

A este respeito, Žižek (2006) aponta o "erro" de Bakhtin em analisar a Lei pública da cultura oficial contraposta por uma transgressão superegoica idealizada na figura da cultura carnavalesca. O que antes era uma transgressão idealizada e exigida de forma implícita tornase hoje a Lei superegoica dessublimada do gozo. A transgressão da Lei hoje é a própria Lei.

Neste momento, retomamos a discussão do cenário de mercadorização da cultura, ou de capitalismo cultural, no qual, por exemplo, o Carnaval torna-se produto cultural. A dimensão do gozo desempenha papel central neste contexto, sendo articulada de maneiras distintas e permitindo operar o imperativo do gozo como fundamento de uma mercadorização irrestrita.

A definição discursiva do que é cultura e de suas diferentes manifestações estabelece as diretrizes e parâmetros segundo os quais as festas populares devem ser realizadas e fruídas - o que é permitido ou não durante os eventos. O saber sobre estas festas populares define também seus diferentes significados, incorporando o conhecimento especializado e a burocracia relativos à festa. Em paralelo, a presença do investimento financeiro que viabiliza ou incrementa esses eventos traz consigo, em última instância a busca pelo retorno financeiro 
adequado correspondente aos esforços de investimento.

Aqui, pensando no carnaval ou em outra festa da cultura popular, esta lógica define, por exemplo, quais facetas da festa popular são relevantes e serão exploradas pela organização de um dado evento, em detrimento de outras; que espaços serão destinados para a circulação livre do público, enquanto outros são definidos como espaços exclusivos, camarotes ou áreas VIP; que grupos são "merecedores” de financiamento, que atrações artísticas estão em alta e são mais relevantes para a viabilização e sucesso do evento.

Neste contexto, as diferentes manifestações e formas de brincar a festa poderiam ser consideradas objetos de desejo do sujeito transformado em consumidor, que apresentaria, sob o signo do imperativo do gozo, a ânsia por vivenciar a festa de maneira autêntica, o que os levaria a explorar todas as possibilidades a fim de fruir a festa em sua plenitude. Uma festa concebida, planejada e preparada dentro do horizonte da experiência de consumo, relegando ao segundo plano a dimensão histórico-cultural na realização dos eventos.

As festas populares são (re) inventadas em sua autenticidade idealizada, atendendo os anseios dos sujeitos-consumidores. A encenação de autenticidade da festa é aceita coletivamente. Contraditoriamente, o planejamento e a preparação na manifestação da cultura popular representa uma espécie de proteção contra o desejo excessivo do sujeito, contra um possível gozo puro (ŽIŽEK, 2010). A inevitável insatisfação proveniente desta contradição evidencia a passagem de uma "sociedade da satisfação administrada para uma sociedade da insatisfação administrada na qual ninguém realmente acredita nas promessas de gozo veiculadas pelo sistema de mercadorias" (SAFATLE, 2008, p. 23).

\section{CONSIDERAÇÕES FINAIS}

Tendo discutido a relação entre a ideologia vigente do imperativo do gozo e o crescente processo de mercadorização da cultura, acreditamos que a sociedade de consumo do capitalismo tardio é marcada pela ubiquidade de mercadorias que assumem a função de objetos $a$ parciais. As mercadorias, ofertadas com diversidade e em abundância, tornam-se objetos de desejo a serem consumidos na ânsia de que sejam a Coisa Real. Entretanto, como este Real é impossível ao sujeito, enquanto ser constituído na linguagem, o fracasso se converte em fonte de mais-gozar, um gozo parcial, absolutamente efêmero e de demanda incessante.

Assumimos que os sujeitos, atendendo ao imperativo superegoico que os pressiona em 
busca do gozo, passam de mercadoria em mercadoria segundo a lógica metonímica de perpetuação do desejo. Em paralelo, a pulsão atua no sentido de transformar cada frustração inevitavelmente gerada pela incapacidade das mercadorias de oferecerem um gozo pleno em mais-gozar, gozos ínfimos que alimentam e perpetuam o movimento circular da pulsão em torno do vazio constitutivo do sujeito.

Dentro da lógica de mercantilização da cultura, o capitalismo coloniza o inconsciente, remetendo-nos a Frederic Jameson. A dimensão simbólica do social é permeada por um inconsciente coletivo supraimaginário, produzido em escala industrial como alternativa de resposta ao mistério do desejo do Outro. Num processo apontado por Maria Rita Kehl (2015) como aperfeiçoamento da alienação, as manifestações concretas singulares do objeto $a$ tornamse obsoletas imediatamente e são descartadas em favor de novas manifestações sintomáticas do nosso anseio em responder ao desejo do Outro.

Dessa forma, entendemos ser por meio desta economia libidinal que o capitalismo cresce e avança em direção à transformação dos mais variados elementos da vida social em mercadorias passíveis de conversão em objetos $a$. A cultura popular, em suas diferentes manifestações, passa a ser também absorvida e assimilada por tal lógica, transformando-se, enquanto uma particularidade concreta, em mais uma dentre tantas mercadorias substitutivas do objeto $a$. A festa carnavalesca surge, então, como um caso representativo desta realidade, em que a celebração tão tradicional da cultura brasileira assume o papel de evento grandioso, capaz de atrair os mais variados interesses.

Ao término deste ensaio teórico, identificamos o potencial de realizar pesquisas voltadas para a investigação empírica de como a relação entre imperativo do gozo e mercadorização da cultura pode ser percebida em diferentes manifestações populares no contexto brasileiro. A exploração empírica desta relação pode oferecer subsídios para compreender melhor a lógica de organização econômico-social que opera na contemporaneidade e seus impactos concretos em termos da atuação de organizações públicas e privadas no processo em marcha de mercadorização da vida cotidiana.

\section{REFERÊNCIAS}

ALTHUSSER, L. Ideologia e aparelhos ideológicos de estado (Notas para uma investigação). In: ŽIŽEK, S. (Org.). Um mapa da ideologia. Rio de Janeiro: Contraponto, 1996. p. 105-142. 
ARANTES, N. Pequena história do Carnaval no Brasil. Revista Portal de Divulgaçãa, v. 3, n. 29, p. 6-20, fev. 2013.

ARAÚJO, H. Carnaval: seis milênios de história. Rio de Janeiro: Gryphus, 2000.

ARAÚJO, R. C. B. Carnaval do Recife: a alegria guerreira. Estudos avançados, v. 11, n. 29, 1997.

BAKHTIN, M. M. A cultura popular na Idade Média e no Renascimento: o contexto de François Rabelais. São Paulo: Hucitec, 1987.

BATISTA, C. M.; ÁVILA, M. A. Patrimônio histórico cultural e turismo no carnaval de Caravelas: axé versus samba. Caderno Virtual de Turismo, jun. 2006.

BECKER, P. A Economia do Gozo. Rio de Janeiro: Garamond, 2010.

CANCLINI, N. G. As culturas populares no capitalismo. São Paulo: Brasiliense, 1983.

CARLSON, H. G. Strindberg and the carnival of history. Scandinavian Studies, v. 62, n. 1, p. 39-52, 1990.

CARNEIRO, N. R. S. A importância do marketing cultural para sobrevivência do carnaval como manifestação popular. Presciência, Recife, n. 1, p. 11-27, mar. 2006.

CEDERSTRÖM, C.; SPICER, A. The Wellness Syndrome. Cambridge: Polity, 2015.

DAMATTA, R. Carnavais, malandros e heróis: para uma sociologia do dilema brasileiro. 6. ed. Rio de Janeiro: Rocco, 1997.

DELGADO, A. K. C. O carnaval como elemento identitário e atrativo turístico: análise do projeto folia de rua em João Pessoa (PB). Cultur - Revista de Cultura e Turismo, v. 6, n. 4, out. 2012.

FARIAS, E. Carnaval carioca, a matriz do negócio do ócio brasileiro. Caderno CRH, Salvador, n. 38, p. 177-208, jan./jun. 2003. 
Quando inovar é apelar à tradição: a condição baiana frente à modernização turística.

Caderno CRH, Salvador, v. 21, n. 54, p. 571-594, set./dez. 2008.

FELDNER, H.; VIGHI, F. Žižek's Notion of Ideology Critique in Context. International Journal of Žižek Studies, v. 4, n. 1, 2009.

FINK, B. O sujeito lacaniano: entre a linguagem e o gozo. Rio de Janeiro: Zahar, 1998.

FONTENELLE, I. A. O trabalho da ilusão: produção, consumo e subjetividade na sociedade contemporânea. Interações, v. 10, n. 19, p. 63-86, jan./jun. 2005.

FRANÇOIA, C. R. O simbólico e a clínica psicanalítica: o início da teoria lacaniana. Revista AdVerbum, v. 2, n. 1, p. 87-101, jan./jun. 2007.

GAIÃO, B. F. S.; LEÃO, A. L. M. S.; MELlO, S. C. B. A Teoria do Discurso do Carnaval Multicultural do Recife: uma análise da festa carnavalesca de Recife à luz da Teoria de Laclau e Mouffe. RAM - Revista de Administração Mackenzie, v. 15, n. 6, Edição Especial, São Paulo, p. 149-171, nov./dez. 2014.

GERMANO, I. O Carnaval no Brasil: da origem europeia à festa nacional. Caravelle, Toulouse, n. 73, p. 131-145, 1999.

JAGUARIBE, B. Carnival crowds. The Sociological Review, v. 61, n. 1, p. 69-88, 2013.

KEHL, M. R. O espetáculo como meio de subjetivação. Revista Concinnitas, v. 1, n. 26, p. 86-96, 2015.

KRIER, D.; SWART, W. J. Trophies of Surplus Enjoyment. Critical Sociology, v. 42, n. 3, p. 371-392, 2016.

KUL-WANT, C.; PIERO. Entendendo Slavoj Zizek: um guia ilustrado. São Paulo: Leya, 2012.

LACAN, J. O estádio do espelho como formador da função do Eu. In: ŽIŽEK, S. (Org.). Um mapa da ideologia. Rio de Janeiro: Contraponto, 1996. p. 97-104. 
LAMPOGLIA, F.; MIOTELLO, V.; ROMÃO, L. M. S. Do desfile na avenida ao camarote: um olhar discursivo sobre o carnaval nos cartuns de Angeli. Linguagem em (Dis)curso, Tubarão, v. 11, n. 1, p. 81-102, jan./abr. 2011.

LEOPOLDI, J. S. Escolas de samba, blocos e o renascimento da carnavalização. Textos escolhidos de cultura e arte populares, Rio de Janeiro, v. 7, n.2, p. 27-44, nov. 2010.

LUSTOSA, M. A. V.; PIRES, M. G. L. O sujeito na experiência psicanalítica e nas narrativas contemporâneas: uma abordagem na filosofia de Žižek. Revista Dialectus, v. 1, n. 1, p. 211230, jul./dez. 2012.

MADRA, Y.; OZSELÇUK, C. Enjoyment as an Economic Factor: Reading Marx with Lacan. Subjectivity, v. 3, n. 3, p. 323-347, 2010.

MUNIZ, R. F. N. Cultura ou mercadoria? Reflexões sobre o carnaval de Itabuna, Bahia. Caderno Virtual de Turismo, Rio de Janeiro, v. 6, n. 4, p. 55-61, 2006.

MYERS, T. Slavoj Žižek. New York: Routledge, 2003.

NOGUEIRA, R. M. F. O carnaval como uma peça da construção identitária brasileira. Caderno Virtual de Turismo, v. 8, n. 1, 2008.

PERNY, M. M.; MELLO, M. D. Máscaras: eu te conheço, carnaval! In: II CONINTER CONGRESSO INTERNACIONAL INTERDISCIPLINAR EM SOCIAIS E HUMANIDADES, 5, 2013, Belo Horizonte. Anais... Belo Horizonte, 2013.

PREFEITURA DO RECIFE. Carnaval Multicultural do Recife. 2015. Disponível em: <http://www.carnavalrecife.com/>. Acesso em: 16 ago. 2015.

QUEIROZ, M. I. P. Carnaval brasileiro: o vivido e o mito. São Paulo: Brasiliense, 1992.

RAMOS, C. Imperativo de gozo e propaganda no laço social da sociedade de consumo. Mental, Barbacena, v. 5, n. 9, p. 101-116, nov. 2007

RISÉRIO, A. Carnaval: as cores da mudança. Afro-Ásia. 1995. Disponível em: <http://www.afroasia.ufba.br/pdf/afroasia_n16_p90pdf.pdf >. Acesso em: 16 ago. 2015. 
SAFATLE, V. P. Destruição e reconfiguração do corpo na publicidade mundial dos anos 90. Comunicação, Mídia e Consumo, São Paulo, v. 1, p. 32-50, 2004.

. Por uma crítica da economia libidinal. Ide, São Paulo, v. 46, p. 27-37, 2008.

SARUP, M. Post-structuralism and Postmodernism. $2^{\mathrm{a}}$ ed. London: Harvester Wheatsheaf, 1993.

SCRIBNER, B. Reformation, carnival and the world turned upside-down. Social History, v. 3, n. 3, p. 303-329, 1978.

SEBE, J. C. Carnaval, Carnavais. São Paulo: Editora Ática, 1986.

SOIHET, R. Reflexões sobre o carnaval na historiografia: algumas abordagens. Academia do samba. $1998 . \quad$ Disponível em: <http://www.academiadosamba.com.br/monografias/raquelsoihet.pdf>. Acesso em: 16 ago. 2015.

TEIXEIRA, V. L.; COUTO, L. F. S. A cultura do consumo: uma leitura psicanalítica lacaniana. Psicologia em Estudo, Maringá, v. 15, n. 3, p. 583-591, jul./set. 2010.

TRIGUEIRO, O. M. A espetacularização das culturas populares ou produtos culturais folkmidiáticos. In: SEMINÁRIO NACIONAL DE POLÍTICAS PÚBLICAS PARA AS CULTURAS POPULARES. Anais... Fevereiro, 2005.

VIDAL, F. M. C.; ANDRADE, E. L. Civilizar para carnavalizar: proposta de um carnaval moderno em Pernambuco (1935-1985). In: XXII SIMPÓSIO INTERNACIONAL PROCESSO CIVILIZADOR. Anais... Recife-PE, 2009.

VISCARDI, A. W.; SOTTANI, S. M. R.; SILVA, E. J. Carnaval: entre a contradição de classes e o produto midiático espetacular. Estação Científica, Juiz de Fora, n. 9, jan./jun. 2013.

YOLAL, M. Authenticity, Commodification, and McDonaldization of Tourism Experiences in the Context of Cultural Tourism. In: SOTIRIADIS, M.; GURSOY, D. The Handbook of Managing and Marketing Tourism Experiences. Emerald Group Publishing Limited, 2016. p. 217-233.

YÚDICE, G. A conveniência da cultura. Belo Horizonte: Editora UFMG, 2013. 
ŽIŽEK, S. Absolute recoil. London: Verso, 2014.

As metástases do gozo: seis ensaios sobre a mulher e a causalidade. Lisboa: Relógio D’Água, 2006.

A visão em paralaxe. São Paulo: Boitempo, 2008a.

Como Ler Lacan. Rio de Janeiro: Zahar, 2010.

Como Marx inventou o sintoma. In: . (Org.). Um mapa da ideologia. Rio de

Janeiro: Contraponto, 1996a. p. 297-333.

Introdução: o espectro da ideologia. In: . (Org.). Um mapa da ideologia. Rio de Janeiro: Contraponto, 1996b. p. 7-38.

Primeiro como tragédia, depois como farsa. São Paulo: Boitempo, 2011.

The fragile absolute: or, why is the Christian legacy worth fighting for?. London: Verso, 2000.

. The sublime object of ideology. London: Verso, 2008b 